\title{
Cleavage of bleomycin hydrolase by caspase-3 during apoptosis
}

\author{
YANG CHEN, RONG XU, JIANGUO CHEN, XIAOYU LI and QIYANG HE \\ Institute of Medicinal Biotechnology, Peking Union Medical College and \\ Chinese Academy of Medical Sciences, Beijing 100050, P.R. China
}

Received March 6, 2013; Accepted April 29, 2013

DOI: $10.3892 /$ or.2013.2484

\begin{abstract}
Bleomycin hydrolase (BLH) affects bleomycin chemotherapy through inactivation of bleomycin with deamination. As a neutral cysteine protease, it also plays various roles in physiological conditions and diseases. However, its mechanism of degradation remains unclear. In the present study, we showed that the levels of BLH were significantly reduced during apoptosis induced by the antitumor agents bleomycin, etoposide and hydroxycamptothecin, and inhibited by the caspase inhibitors Q-VD-oph and Z-DEVD-FMK. Furthermore, the caspase-dependent cleavage of BLH was confirmed by cleavage of partly-purified human BLH with caspase-3 and caspase- 9 in vitro. The stability of BLH at normal culture conditions was analyzed with the protein synthesis inhibitor cycloheximide and the proteasome inhibitor MG132. BLH was degraded at a rate lower than that of cyclin D1. This is the first report to demonstrate that BLH is cleaved by caspase-3 during apoptosis.
\end{abstract}

\section{Introduction}

Bleomycin hydrolase (BLH), a member of the papain family of cysteine proteases, is metabolically inactivated antitumor antibiotic bleomycin (BLM) by deamination (1). It functions as a tumor suppressor gene in hepatocellular carcinoma (2). Accumulating data show that BLH plays multifaceted roles under different physiological and pathological conditions, including preparation of peptides for antigen presentation (3), involvement in the pathogenesis of Alzheimer's disease $(4,5)$, detoxification of homocysteine thiolactone (6), N-terminal proteolysis of mutant huntingtin (7) and breakdown of deiminated filaggrin into amino acids (8). Analysis of the human BLH gene indicates that its features are shared by those characteristic of housekeeping genes $(9,10)$. For example, BLH is expressed at high levels in human tissues except for the

Correspondence to: Professor Qiyang He, Institute of Medicinal Biotechnology, Peking Union Medical College and Chinese Academy of Medical Sciences, 1 Tiantan Xili, Beijing 100050, P.R. China

E-mail: qiyang_he@vip.163.com

Key words: bleomycin hydrolase, apoptosis, caspase-3, protein degradation kidneys and lungs $(11,12)$. We recently demonstrated that BLH serves as a biomarker for predicting the efficacy of treatment of tumors with BLM (13).

The level of BLH in tumor cells affects the efficacy of BLM (13-16). Therefore, it is necessary to understand how BLH is regulated to facilitate the development of new antibiotics structurally related to BLM and to demonstrate the pathological roles in the diseases. Therefore, in the present study we determined the stability of BLH in human tumor cells.

\section{Materials and methods}

Drugs and chemicals. BLM was purchased from Nippon Kayaku (Tokyo, Japan) and was dissolved in phosphate-buffered saline (PBS) at $5 \mathrm{mg} / \mathrm{ml}$ and stored at $-20^{\circ} \mathrm{C}$ prior to use. Hydroxycamptothecin (HCPT) was purchased from Shenzhen Wanle Pharmaceutical Co., Ltd., (Guangzhou, China) and was dissolved in PBS at $2 \mathrm{mg} / \mathrm{ml}$. Caspase inhibitors Q-VD-oph and Z-DEVD-FMK were purchased from R\&D Systems Inc. (Minneapolis, MN, USA) and dissolved in dimethyl sulfoxide (DMSO) before use. Cycloheximide (CHX) was purchased from Millipore (Billerica, MA, USA) and dissolved in ethanol at $100 \mathrm{mg} / \mathrm{ml}$. Etoposide (VP-16), Z-Leu-Leu-Leu-al (MG132), and all the chemicals except for those specifically mentioned were purchased from Sigma-Aldrich Inc. (St. Louis, MO, USA). VP-16 and MG132 were dissolved in DMSO at $50 \mathrm{mM}$.

Cell lines and cell culture. The HeLa human cervical cancer cell line was purchased from the American Type Culture Collection (ATCC; Rockville, MD, USA) and the human colon carcinoma HCT-116 cell line was a gift from Bert Vogelstein (Johns Hopkins University, Baltimore, MD, USA). The cell lines were cultured in Dulbecco's modified Eagle's medium supplemented with $10 \%$ fetal bovine serum (Thermo Fisher Scientific Inc., Waltham, MA, USA). All cultures were maintained in an incubator at $37^{\circ} \mathrm{C}$ in a humidified atmosphere with $5 \% \mathrm{CO}_{2}$.

Western blotting. The method was performed according to the protocol previously published (13). The sources of primary antibodies were as follows: rabbit-anti-cleaved/total PARP-1 (9532), rabbit-anti-cleaved caspase-3 (9661) and cleaved caspase-9 (9501), all from Cell Signaling Technology, Inc. (Danvers, MA, USA). The rabbit-anti-BLH (sc-68888), mouse-anti-His tag (sc-804) and mouse-anti-actin (sc-1616) were from Santa Cruz Biotechnology, Inc. (Santa Cruz, CA, USA). All primary antibodies were diluted to 1:1,000. 
Detection of apoptotic cells by Annexin V-FITC/propidium iodide. To quantify apoptosis, cells were stained with Annexin $\mathrm{V}$ and propidium iodide (PI) using an Annexin V-FITC/PI Apoptosis kit (BD Biosciences, San Jose, CA, USA), following the protocol provided by the manufacturer. The fluorescence intensity was measured using a BD FACSCalibur flow cytometer.

Heterologous expression and purification of recombinant human BLH. Human BLH gene was cloned using RT-PCR with the forward primer 5'-CGCGGATCCATGAGCAGCT CGGGACTGAATTCG-3' and the reverse primer 5'-CCG CTCGAGTCACTCAGCCAAAGCTCCCATG-3', which contain the initiator methionine and termination codons and the BamHI and XhoI restriction sites, respectively, as indicated by the underlined bases. cDNA of the template was isolated from $293 \mathrm{~T}$ cells. The cDNA was amplified for 25 cycles as follows: denaturing for $15 \mathrm{sec}$ at $98^{\circ} \mathrm{C}$, annealing for $90 \mathrm{sec}$ at $60^{\circ} \mathrm{C}$, and primer extension for $30 \mathrm{sec}$ at $72^{\circ} \mathrm{C}$. PCR was carried out using PrimeSTAR HS DNA polymerase kit from Takara Bio Inc. The product was cloned into the BamHI and XhoI restriction sites of cDNA3.1 (Invitrogen) and completely sequenced in both directions. E. coli BL21 (DE3) expressing recombinant BLH was generated as described above, following cloning of BLH cDNA into the BamHI and XhoI site of the pET32a (Novagen, Darmstadt, Germany). Expression of recombinant BLH was induced with $1 \mathrm{mM}$ IPTG. Bacterial cells were sonicated and lysates were cleared by centrifugation at $12,000 \mathrm{x}$ g at $4^{\circ} \mathrm{C}$ for $15 \mathrm{~min}$. The supernatants were used for affinity purification on a column containing Ni-NTA-agarose. Protein concentrations of cell lysates were determined using the Bio-Rad Protein Assay. The BLH content was determined in comparison with BSA using SDS-PAGE.

Assay of BLH activity by high performance liquid chromatography. The metabolism of bleomycin was assessed using high performance liquid chromatography (HPLC), which separates bleomycin A2 and B from their inactive metabolites. Briefly, partially-purified BLH $(2 \mathrm{mg} / \mathrm{ml})$ was incubated with $5 \mu \mathrm{g} \mathrm{BLM}$ in $40 \mu \mathrm{l}$ of reaction buffer (20 mM Tris, $\mathrm{pH} 7.5$ ), at $37^{\circ} \mathrm{C}$ for $1 \mathrm{~h}$. The reaction was stopped by the addition of $10 \mu \mathrm{l}$ of methanol, the mixture was centrifuged, and the resulting supernatant fractions were injected into a ZORBAX Eclipse Plus C18 column (4.6 x 250 mm; Agilent Technology Inc., Santa Clara, CA, USA). The mixtures were eluted at $1 \mathrm{ml} / \mathrm{min}$ with $6 \%$ methanol, $6 \%$ acetonitrile and $88 \%$ acetic acid $(\mathrm{pH} 4.2)$ and were detected by their absorbance at $254 \mathrm{~nm}$.

Assays of BLH cleavage in vitro. Partially-purified BLH (50 ng) was incubated with 0.1 unit caspase-6, -8, -9 and-10 (BioVision, Mountain View, CA, USA), respectively, in $20 \mu \mathrm{l}$ reaction buffer (50 mM HEPES, $\mathrm{pH} 7.2,0.1 \%$ CHAPS, $10 \mathrm{mM}$ EDTA, 5\% glycerol, $10 \mathrm{mM}$ DTT, $50 \mathrm{mM} \mathrm{NaCl}$ and $100 \mathrm{mg} / \mathrm{ml} \mathrm{BSA}$ ) at $37^{\circ} \mathrm{C}$ for $1 \mathrm{~h}$, or with $150 \mathrm{ng}$ caspase-3 (Sigma-Aldrich) in $20 \mu \mathrm{l}$ reaction buffer $(10 \mathrm{mM}$ HEPES, $\mathrm{pH} 7.0,5 \mathrm{mM} \mathrm{MgCl}_{2}, 5 \mathrm{mM}$ EDTA, $10 \%$ glycerol, $1 \mathrm{mM}$ DTT, $50 \mathrm{mM} \mathrm{NaCl}$ and $100 \mathrm{mg} / \mathrm{ml} \mathrm{BSA}$ ) at $30^{\circ} \mathrm{C}$ for $1 \mathrm{~h}$. The inhibition of BLH cleavage by caspases was confirmed using $20 \mu \mathrm{M}$ Q-VD-oph. The resulting mixtures were separated by SDS-PAGE and detected by western blotting.
Statistical analysis. SPSS 17.0 software was used for statistical analysis. Student's t-test was applied for comparing the means of 2 groups and a P-value of $<0.05$ was considered to indicate a statistically significant difference.

\section{Results}

Reduction of BLH levels during apoptosis. To verify whether the expression level of BLH was affected during apoptosis, HCT-116 cells were treated for $48 \mathrm{~h}$ with lethal concentrations of BLM or HCPT. The results showed that the level of BLH was markedly reduced by treatment with high concentrations of drug (Fig. 1A and B). Similar results were obtained within $48 \mathrm{~h}$ when HeLa cells were exposed to BLM and VP-16 (Fig. 1C and D).

The presence of apoptotic cells was confirmed by Annexin V/ PI staining after HCT-116 cells were treated with $2 \mu \mathrm{M} \mathrm{HCPT}$ for different times (Fig. 1E). Approximately 53\% of cells showed apoptotic features after exposure to HCPT for $24 \mathrm{~h}$. The levels of BLH and activation of the caspase pathway were monitored after exposure to $2 \mu \mathrm{M}$ HCPT (Fig. 1F). Upregulation of BLH expression was detected after treatment with $2 \mu \mathrm{M}$ HCPT for $8 \mathrm{~h}$. The reduction of BLH levels began at $24 \mathrm{~h}$. Activation of caspase-3 and caspase-9 was observed within 8-12 h. The times at which BLH was degraded were similar to those for cleavage of PARP-1. The data suggest that the degradation of BLH was triggered by the intrinsic apoptotic pathway.

Cleavage of BLH by caspases during apoptosis. To identify the mechanism for the reduction of the levels of BLH due to cleavage by caspase during apoptosis, the broad-spectrum pan-caspase inhibitor Q-VD-oph was used. The cleavage of PARP-1 and the levels of BLH were reduced after exposure to $1 \mu \mathrm{M}$ HCPT by treatment of HCT-116 cells with $20 \mu \mathrm{M}$ Q-VD-oph (Fig. 2A, lanes 3, 4 and B), indicating that cleavage of BLH was caspase dependent. We compared the sequence of BLH with recognition consensus of caspases. Only 1 potential cleavage site for caspase-3 was found. It localizes to Asp39 in the N-terminus of BLH (DLLD), a caspase-3 specific consensus recognition sequence (17). The reduction in the level of BLH was significantly inhibited by the caspase-3-specific inhibitor Z-DEVD-FMK (Fig. 2C and D), consistent with the predicted presence of a caspase-3 recognition site. Similar results were also observed during apoptosis of HeLa cells induced by BLM and VP-16 (data not shown).

Hydrolysis of $B L M$ by recombinant $B L H$. The findings described above that degradation of BLH is caspase-dependent prompted us to further characterize the cleavage of BLH in vitro. Human recombinant BLH was expressed in $E$. coli BL21 and partially purified using a Ni-NTA-agarose column. The concentration of the resultant recombinant protein was estimated to be $\sim 2 \mathrm{mg} / \mathrm{ml}$. The activity of recombinant BLH was confirmed by its ability to hydrolyze BLM, and the resultant reaction mixtures were analyzed using reversed phase chromatography monitored at $254 \mathrm{~nm}$. The results showed that the recombinant BLH converted BLM-A2 and B2 to its known metabolites, and the hydrolysis of BLM-B2 was faster than that of BLM-A2, with most B2 hydrolyzed at 20 min and only approximately two-thirds of A2 at 60 min (Fig. 3). 

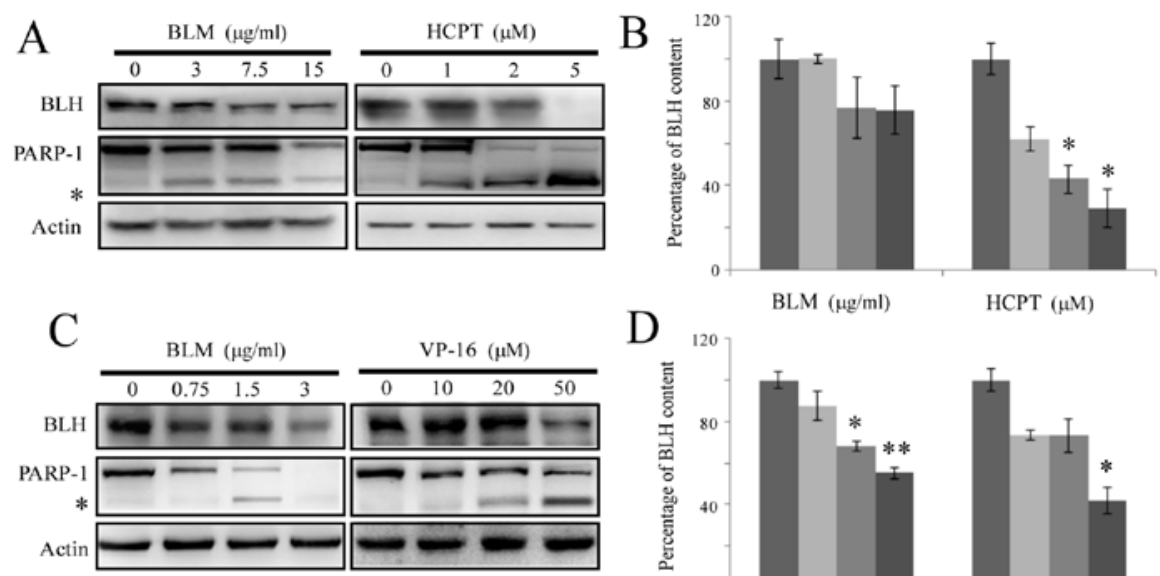

$\mathrm{D}$

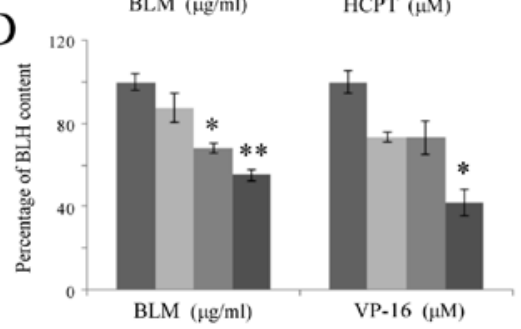

$\mathrm{E}$
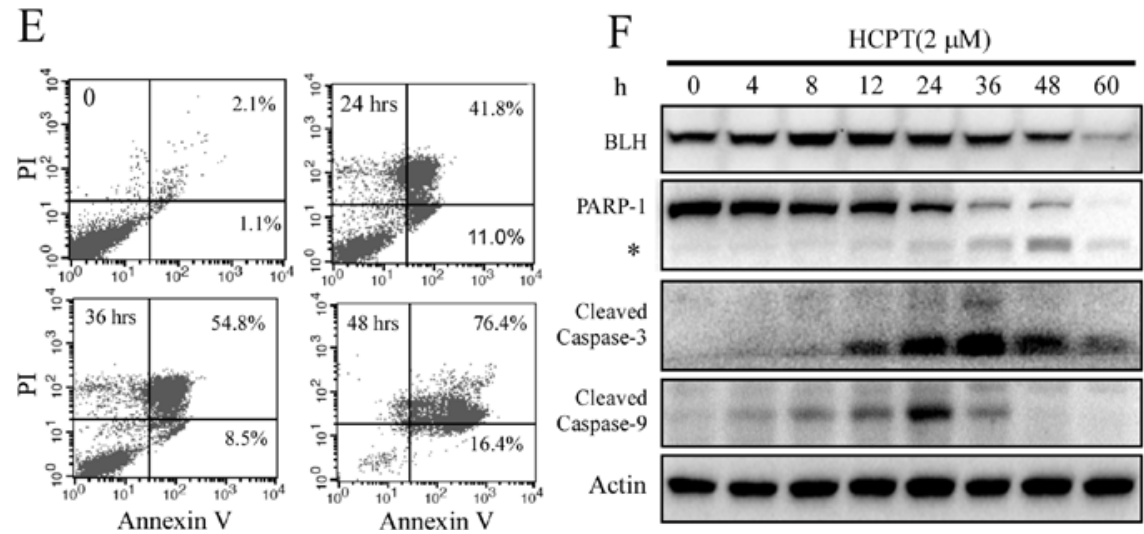

Figure 1. Reduction of the levels of BLH during apoptosis. (A) BLH degradation was detected by western blotting after HCT-116 cells were treated with high concentrations of BLM and HPCT for $48 \mathrm{~h}$. (B) The percentage of BLH levels in the HCT-116 cells is presented as mean \pm standard deviation (SD) from 3 independent experiments. (C) The apoptosis of HeLa cells was induced using high concentrations of BLM and VP-16 for $48 \mathrm{~h}$ and cell lysates were analyzed using western blotting. (D) The percentage of BLH levels in HeLa cells is presented as mean \pm SD from 3 independent experiments. ${ }^{*} \mathrm{P}<0.05$ and ${ }^{* *} \mathrm{P}<0.005$. (E) Apoptotic cells were detected by Annexin V/PI staining after HCT-116 cells were treated with $2 \mu \mathrm{M}$ HCPT for 24, 36 and 48 h. (F) Reduction of BLH levels over time and activation of caspase pathway after HCT-116 cells were exposed to $2 \mu \mathrm{M}$ HCPT from 0 to $60 \mathrm{~h}$. The levels of BLH, PARP-1 and other proteins relevant to apoptosis were analyzed by western blotting. The levels of actin were shown as loading controls. In E and F, 1 representative result from 3 independent experiments is shown.

A
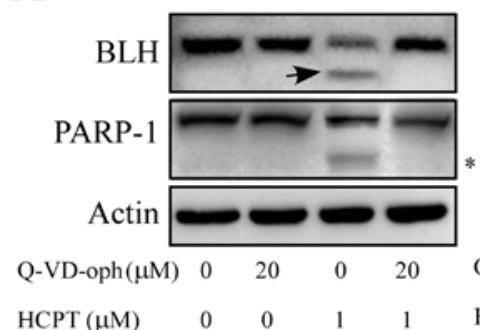

$\mathrm{C}$

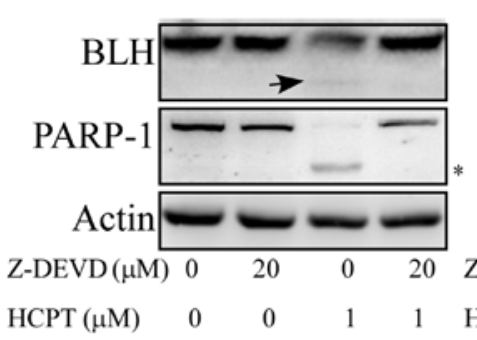

B

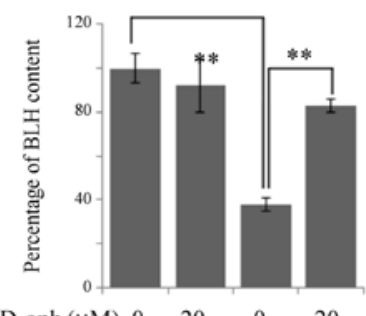

Q-VD-oph $(\mu \mathrm{M}) \quad 0 \quad 20 \quad 0 \quad 20$

$\operatorname{HCPT}(\mu \mathrm{M}) \quad 0 \quad 001101$

$\mathrm{D}$

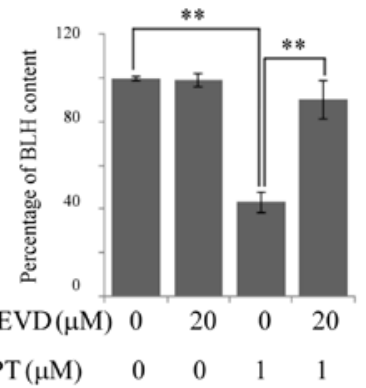

Figure 2. Caspase-dependent reduction of BLH level. (A) Cleavage of BLH was inhibited by the general caspase inhibitor Q-VD-oph after HCT-116 cells were treated with $1 \mu \mathrm{M}$ HCPT plus $20 \mu \mathrm{M}$ Q-VD-oph for $48 \mathrm{~h}$. The protein levels of BLH and PARP-1 were analyzed by western blotting. (B) The percentage of BLH levels in HCT-116 cells is presented as mean \pm SD from 3 independent experiments. (C) Cleavage of BLH was inhibited by the caspase-3-specific inhibitor Z-DEVD-FMK after HCT-116 cells were treated with $1 \mu \mathrm{M}$ HCPT plus $20 \mu \mathrm{M}$ Z-DEVD-FMK for $48 \mathrm{~h}$. (D) The percentage of BLH levels in HCT-116 cells is presented as mean \pm SD from 3 inpendent experiments. ${ }^{*} \mathrm{P}<0.05,{ }^{* * *} \mathrm{P}<0.005$. The asterisk $\left(^{*}\right)$ indicates a cleaved fragment of PARP-1 and the arrow marks a fragment of BLH. 

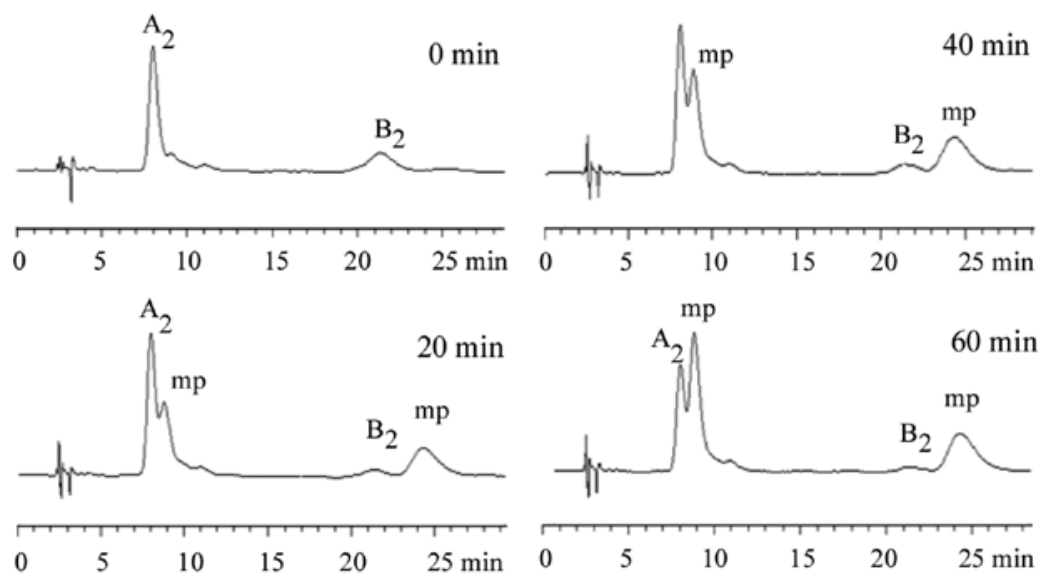

Figure 3. Assay of the activity of recombinant BLH. Time points of the hydrolysis of bleomycin A2 and B2 by recombinant BLH were measured using HPLC (mp, metabolic products). One representative result from 3 independent experiments is shown.
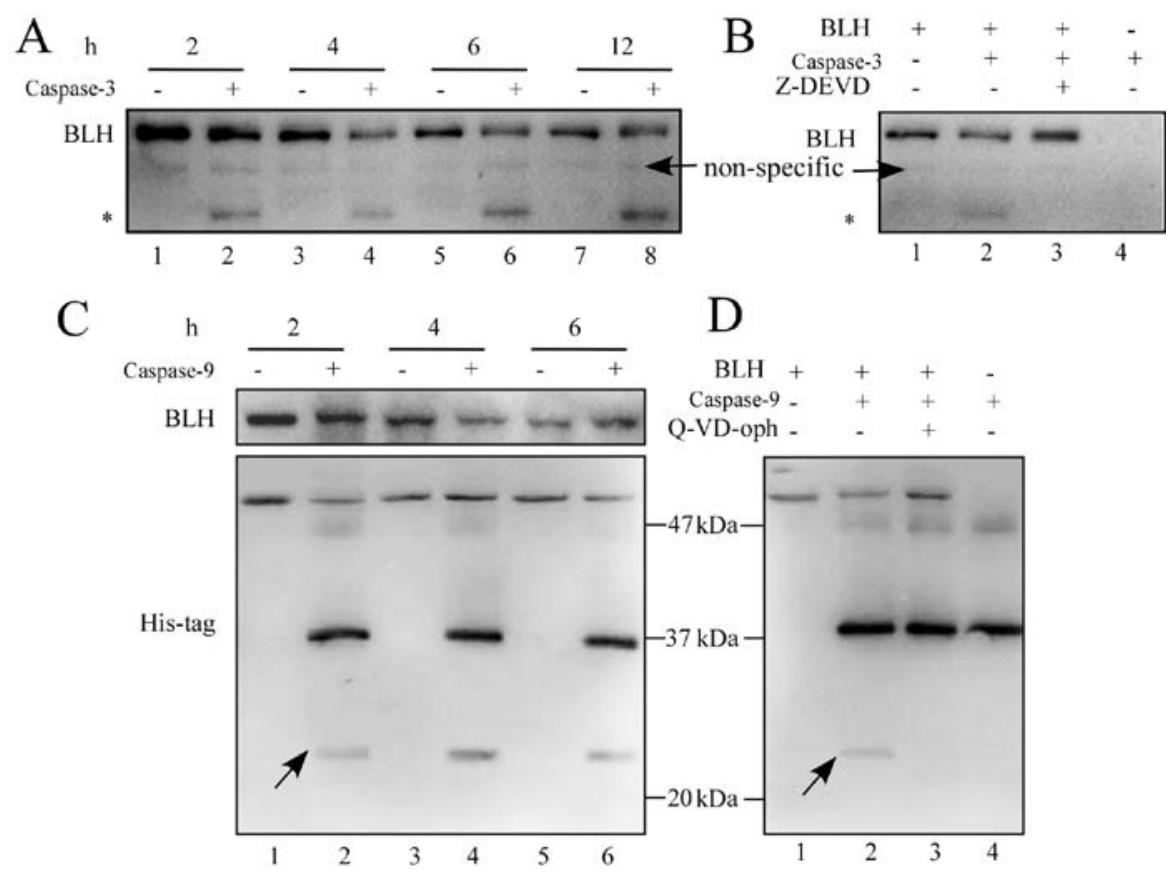

Figure 4. Cleavage of BLH by caspase- 3 and caspase- 9 in vitro. (A) Recombinant BLH (50 ng) was incubated with purified caspase- $3(50 \mathrm{ng})$ at $30^{\circ} \mathrm{C}$ for 2,4 , 6 and $12 \mathrm{~h}$ and the reaction mixtures were subjected to western blotting using 12.5\% SDS-PAGE gel and an anti-BLH antibody (lanes 1-8). (B) Cleavage of BLH by caspase- 3 was specifically inhibited by $20 \mu \mathrm{M}$ Z-DEVD-FMK. Lane 1, BLH alone; lane 2, BLH plus caspase-3 for $2 \mathrm{~h}$; lane 3, BLH plus caspase-3 and Z-DEVD-FMK; lane 4, $50 \mathrm{ng}$ caspase-3 alone. (C) Recombinant BLH $(50 \mathrm{ng})$ was incubated at $37^{\circ} \mathrm{C}$ with purified caspase-9 $(1 \mathrm{unit})$ for 2,4 and $6 \mathrm{~h}$, and the reaction mixtures were subjected to western blotting using a 12.5\% SDS-PAGE gel and anti-His Tag antibody (lanes 1-6). (D) Cleavage of BLH by caspase-9 was inhibited by $20 \mu \mathrm{M}$ Q-VD-oph. Lane 1, BLH alone; lane 2, BLH plus caspase-9 for $2 \mathrm{~h}$; lane 3, BLH plus caspase-9 and Q-VD-oph; lane 4, 1 unit caspase-9 alone. The asterisk $(*)$ indicates a fragment of BLH. One representative result from 3 independent experiments is shown.

Cleavage of BLH by caspase-3 and caspase-9 in vitro. We incubated recombinant BLH in vitro with caspase-3, -6, -8, -9 and -10 , respectively. Recombinant BLH was only cleaved detectably by caspase- 3 and caspase- 9 . When the recombinant $\mathrm{BLH}$ was incubated with purified caspase- 3 at $37^{\circ} \mathrm{C}$, both its degradation product and cleaved band were detected over a period of $12 \mathrm{~h}$ (Fig. 4A). The caspase-3-specific inhibitor Z-DEVD-FMK inhibited degradation of BLH (Fig. 4B). The small amount of BLH cleavage by caspase-9 was also detected using an anti-His Tag antibody but not by an anti-BLH antibody (Fig. 4C). This cleavage reaction was inhibited by Q-VD-oph (Fig. 4D).
Lower rate of $B L H$ degradation at normal culture conditions. To determine whether the degradation of BLH is involved in the ubiquitin-proteasome pathway, de novo protein synthesis was blocked with the protein synthesis inhibitor CHX under normal culture conditions. The stability of short-lived cyclin D1 was monitored for comparison. Treatment of HCT-116 cells with $20 \mu \mathrm{g} / \mathrm{ml} \mathrm{CHX}$ resulted in a time-dependent reduction of the cyclin D1 levels, and only $50 \%$ of its initial level remained after exposure to $\mathrm{CHX}$ for $1 \mathrm{~h}$. By contrast, the level of BLH remained constant initially and was then reduced by $\sim 20 \%$ after treatment with $\mathrm{CHX}$ for $4 \mathrm{~h}$ (Fig. 5A and B). A small amount of the cleaved PARP fragment was observed at $4 \mathrm{~h}$, 

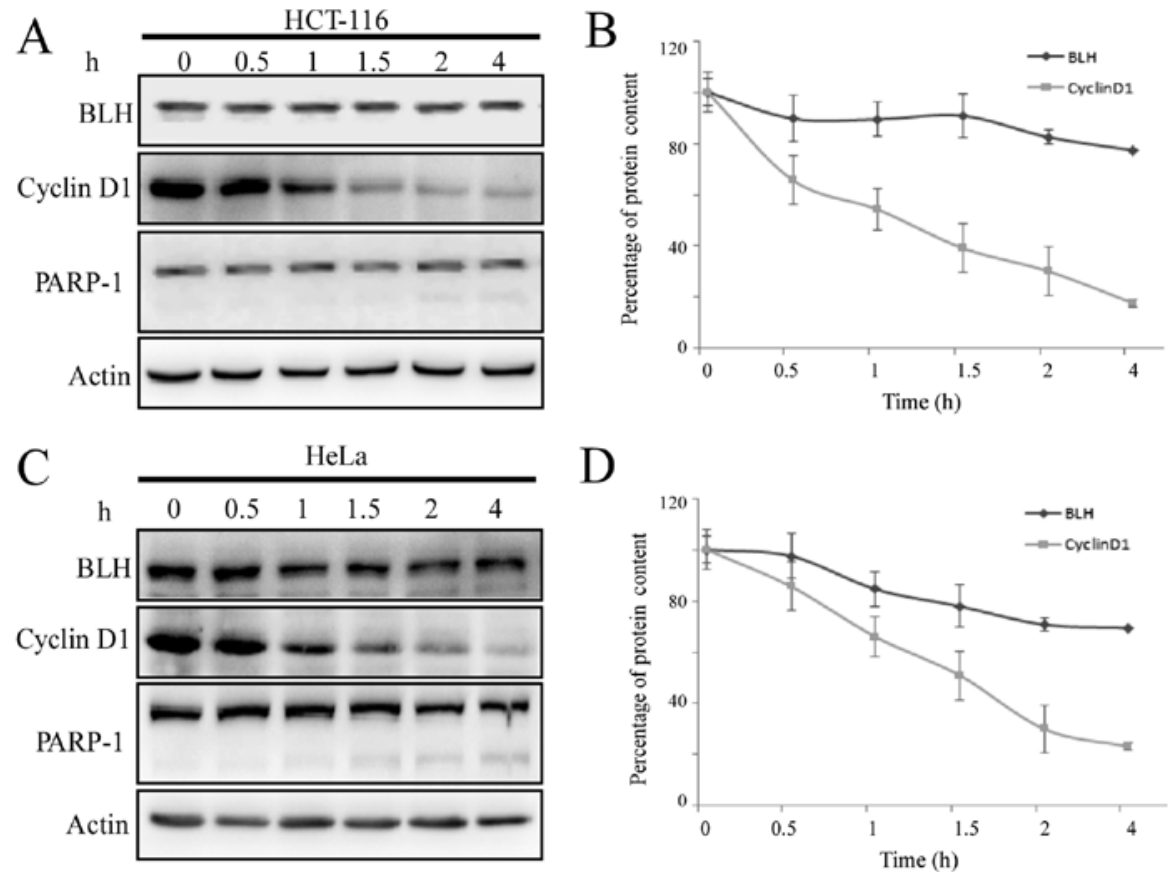

Figure 5. Lower degradation of BLH under normal cell culture conditions. (A) HCT-116 cells and (C) HeLa cells were treated with $20 \mu \mathrm{g} / \mathrm{ml}$ cycloheximide for $0.5,1,1.5,2$ and $4 \mathrm{~h}$. The levels of BLH, cyclin D1 and PARP-1 were analyzed using western blotting. Actin levels are shown as loading controls. (B and D) Densitometric quantification of the western blot results. Each value represents the mean \pm SD of 3 samples from 3 independent experiments.

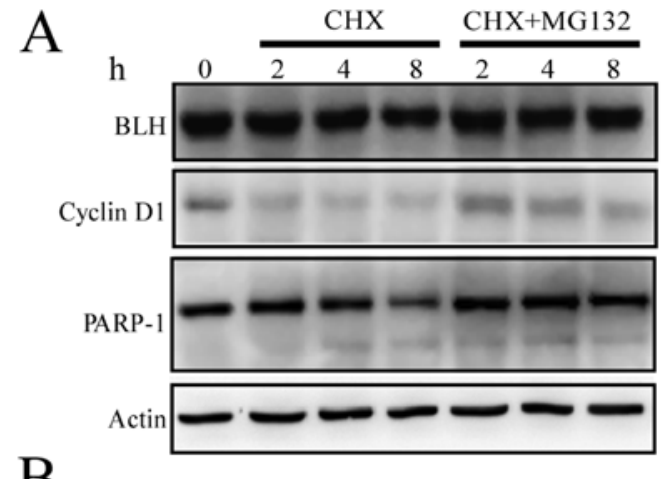

B

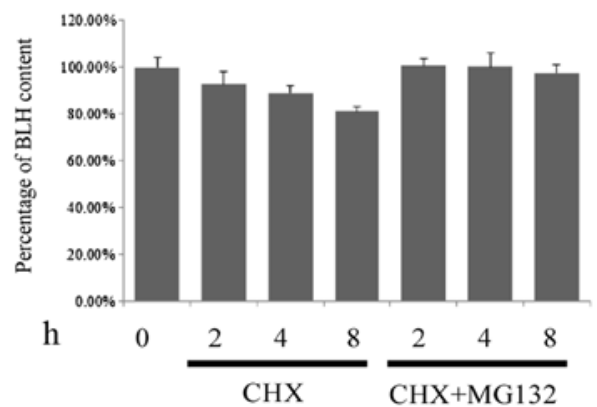

Figure 6. Involvement of the ubiquitin-proteosome pathway in the degradation of BLH. (A) HCT-116 cells were treated with $20 \mu \mathrm{g} / \mathrm{ml}$ cycloheximide or cycloheximide plus $50 \mu \mathrm{M}$ specific inhibitor MG132 for 2, 4 and $8 \mathrm{~h}$. The levels of BLH and cyclin D1 were analyzed using western blotting. Actin levels are shown as loading controls. (B) Densitometric quantification of the western blot results. Each value represents the mean \pm SD of 3 samples from 3 independent experiments.

suggesting induction of apoptosis by $\mathrm{CHX}$. This prevented us from further calculations of the half-life of BLH degradation using this method. These same results were obtained using HeLa cells (Fig. 5C and D).
To verify whether BLH is degraded via the ubiquitinproteasome pathway, HCT-116 cells were treated with CHX plus $50 \mu \mathrm{M}$ MG132, a specific inhibitor of the ubiquitin-proteasome pathway. The degradation of cyclin D1 was completely suppressed, and degradation of BLH was also inhibited (Fig. 6), indicating that BLH is degraded via the ubiquitinproteasome pathway.

\section{Discussion}

In the present study, we investigated the degradation of BLH under different conditions. To the best of our knowledge, this is the first report showing that degradation of BLH is caspasedependent during apoptosis and that BLH can be cleaved by caspase- 3 and caspase- 9 in vitro. In apoptotic pathways, caspases act as signal transducers, directing the cell toward death by cleaving numerous substrates (18). We identified a caspase-3 recognition site at Asp39 in the N-terminus of BLH (DLLD), but no site for caspase-9. This could be explained by the requirement for a tertiary structure, as caspases can cleave at 'non-canonical' sites, such as the viral caspase inhibitor p35 bound to caspase-8 (19).

Our present results are consistent with data of others

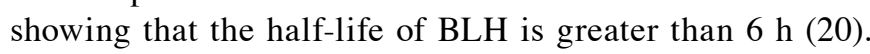
However, we could not determine the half-life of BLH precisely, as $\mathrm{CHX}$ treatment led to apoptotic degradation of BLH. Protein stability plays a role in the abundance of cellular proteins, and several housekeeping proteins tend to have stable mRNAs and proteins to improve energy efficiency (21). The function of BLH is evolutionarily conserved from yeasts to humans and the yeast homologue of BLH metabolizes BLM in mammalian cells (22). The features of $B L H$ are characteristic of housekeeping genes (9). The relationship between 
stability of BLH and its function is being investigated in our laboratory.

BLH can hydrolyze the bleomycin to generate the inactive deamino form. The mice with knockout of BLH gene are very sensitive to bleomycin (15). The patients with homozygous variant G/G of BLH gene SNP (A1450G) are associated with reduced survival in testicular germ cell cancer (16). The expression of BLH increased after exposure to low concentrations of bleomycin (13). All data indicate that the BLH level plays an important roles in bleomycin action. The present results provide new evidence for the regulation of BLH level that may aid in the translational development of new bleomycin-related antibiotics.

Loss of BLH leads to astrogliosis and behavioral changes in mice (23), suggesting its importance in the functions of neurons. Although it has not been confirmed that genetic polymorphisms of $B L H$ are involved in the genesis of Alzheimer's disease, regulation of the secretion of amyloid precursor protein by BLH plays a function (5). Accumulating data show that apoptosis of neurons is involved in the genesis of Alzheimer's disease (24). Furthermore, the levels of BLH activity are reduced in patients with Alzheimer's disease (4). This finding might be explained by the degradation of BLH during the apoptosis of neurons by a mechanism similar to that demonstrated here.

In summary, the degradation of BLH can occur through the caspase- 3 and ubiquitin-proteasome pathways. The results presented here facilitate further studies of BLH functions under different physiological and pathological conditions.

\section{Acknowledgements}

The present study was supported by grants from the National Scientific Foundation of China (81273553) and the National S\&T Major Special Project on Major New Drug Innovation (2012ZX09301002-001-015).

\section{References}

1. Chen J and Stubbe J: Bleomycins: towards better therapeutics. Nat Rev Cancer 5: 102-112, 2005.

2. Okamura Y, Nomoto S, Hayashi M, et al: Identification of the bleomycin hydrolase gene as a methylated tumor suppressor gene in hepatocellular carcinoma using a novel triple-combination array method. Cancer Lett 312: 150-157, 2011.

3. Towne CF, York IA, Watkin LB, Lazo JS and Rock KL: Analysis of the role of bleomycin hydrolase in antigen presentation and the generation of CD8 T cell responses. J Immunol 178: 6923-6930, 2007.

4. Suszynska J, Tisonczyk J, Lee HG, Smith MA and Jakubowski H: Reduced homocysteine-thiolactonase activity in Alzheimer's disease. J Alzheimers Dis 19: 1177-1183, 2010.

5. Lefterov IM, Koldamova RP and Lazo JS: Human bleomycin hydrolase regulates the secretion of amyloid precursor protein. FASEB J 14: 1837-1847, 2000.
6. Zimny J, Sikora M, Guranowski A and Jakubowski H: Protective mechanisms against homocysteine toxicity: the role of bleomycin hydrolase. J Biol Chem 281: 22485-22492, 2006.

7. Ratovitski T, Chighladze E, Waldron E, Hirschhorn RR and Ross CA: Cysteine proteases bleomycin hydrolase and cathepsin $\mathrm{Z}$ mediate $\mathrm{N}$-terminal proteolysis and toxicity of mutant huntingtin. J Biol Chem 286: 12578-12589, 2011.

8. Kamata Y, Taniguchi A, Yamamoto M, Nomura J, Ishihara K, Takahara H, Hibino T and Takeda A: Neutral cysteine protease bleomycin hydrolase is essential for the breakdown of deiminated filaggrin into amino acids. J Biol Chem 284: 12829-12836, 2009.

9. Ferrando AA, Pendás AM, Llano E, Velasco G, Lidereau R and López-Otín C: Gene characterization, promoter analysis, and chromosomal localization of human bleomycin hydrolase. J Biol Chem 272: 33298-33304, 1997.

10. Ferrando AA, Velasco G, Campo E and Lopez-Otin C: Cloning and expression analysis of human bleomycin hydrolase, a cysteine proteinase involved in chemotherapy resistance. Cancer Res 56: 1746-1750, 1996.

11. Brömme D, Rossi AB, Smeekens SP, Anderson DC and Payan DG: Human bleomycin hydrolase: molecular cloning, sequencing, functional expression, and enzymatic characterization. Biochemistry 35: 6706-6714, 1996.

12. Montoya SE, Ferrell RE and Lazo JS: Genomic structure and genetic mapping of the human neutral cysteine protease bleomycin hydrolase. Cancer Res 57: 4191-4195, 1997.

13. Chen J, Chen Y and He Q: Action of bleomycin is affected by bleomycin hydrolase but not by caveolin-1. Int $\mathrm{J}$ Oncol 41: 2245-2252, 2012

14. Lazo JS, Boland CJ and Schwartz PE: Bleomycin hydrolase activity and cytotoxicity in human tumors. Cancer Res 42: 4026-4031, 1982.

15. Schwartz DR, Homanics GE, Hoyt DG, Klein E, Abernethy J and Lazo JS: The neutral cysteine protease bleomycin hydrolase is essential for epidermal integrity and bleomycin resistance. Proc Natl Acad Sci USA 96: 4680-4685, 1999.

16. De Haas EC, Zwart N, Meijer C, et al: Variation in bleomycin hydrolase gene is associated with reduced survival after chemotherapy for testicular germ cell cancer. J Clin Oncol 26: 1817-1823, 2008.

17. Timmer JC and Salvesen GS: Caspase substrates. Cell Death Differ 214: 66-72, 2007.

18. Crawford ED and Wells JA: Caspase substrates and cellular remodeling. Annu Rev Biochem 80: 1055-1087, 2011.

19. Xu G, Cirilli M, Huang Y, Rich RL, Myszka DG and Wu H: Covalent inhibition revealed by the crystal structure of the caspase-8/p35 complex. Nature 410: 494-497, 2001.

20. Koldamova RP, Lefterov IM, DiSabella MT and Lazo JS: An evolutionarily conserved cysteine protease, human bleomycin hydrolase, binds to the human homologue of ubiquitin-conjugating enzyme 9. Mol Pharmacol 54: 954-961, 1998.

21. Schwanhäusser B, Busse D, Li N, Dittmar G, Schuchhardt J, Wolf $\mathrm{J}$, et al: Global quantification of mammalian gene expression control. Nature 473: 337-342, 2011.

22. Pei Z, Calmels TP, Creutz CE and Sebti SM: Yeast cysteine proteinase gene ycp1 induces resistance to bleomycin in mammalian cells. Mol Pharmacol 48: 676-681, 1995.

23. Montoya SE, Thiels E, Card JP and Lazo JS: Astrogliosis and behavioral changes in mice lacking the neutral cysteine protease bleomycin hydrolase. Neuroscience 146: 890-900, 2007.

24. Chaitanya GV, Steven AJ and Babu PP: PARP-1 cleavage fragments: signatures of cell-death proteases in neurodegeneration. Cell Commun Signal 8: 31, 2010. 